\title{
Analyze the Future: Cloud Computing, a New Phase in Information Technology Infrastructure Management
}

\author{
Vartika Kulshrestha ${ }^{1}$, Dr. Seema Verma ${ }^{2}$ \\ ${ }^{1,2}$ Dept. of Electronics, Banasthali Vidyapith, Banasthali, Newai - 304022, Rajasthan \\ vartikakul@gmail.com \\ seemaverma3@yahoo.com
}

\begin{abstract}
The use of cloud computing is becoming widespread, but systematic study of its managerial implications is lacking. This paper examines cloud computing in the context of other major changes in Information Technology (IT) and explores the revolutionary transformations and challenges which bring to IT management. Cloud computing has a high reliability, low cost and good availability. With the increasing use of technology in modern era, there is a growing requirement of information technology infrastructure management. Over some decades in the past, organizations have put their efforts in the development and application of information technology to collect, analyze and process the data. Various computing paradigms have been employed for the purpose and needs have emerged for enormous infrastructure.

Cloud Computing is evolving as a key computing platform for sharing resources that include infrastructure, software application and business processes. Virtualization is a core technology for enabling cloud resources sharing [1]. Virtualization refers to the abstracting of a form of technology away from its original environment. The benefit derives from being able to redeliver it in a virtual (or "logical") form capable of the same functionality as the original, but with greater flexibility [2]. This paper presents how Cloud Computing service model - Infrastructure as a Service (laaS) can be used to meet the increasing demands of the Information Technology Infrastructure Management and how Cloud Computing paradigm can prove to be future solution for such systems. With laaS, IT services can be delivered as a subscription service, eliminating up-front costs and driving down ongoing support costs.
\end{abstract}

\section{Keywords}

Cloud Computing; Virtualization; Information Technology; laaS; Datacenter.

\section{Council for Innovative Research}

Peer Review Research Publishing System

\author{
Journal: INTERNATIONAL JOURNAL OF COMPUTERS \& TECHNOLOGY
}

\author{
Vol 11, No. 6 \\ editor@cirworld.com \\ www.cirworld.com, member.cirworld.com
}




\section{INTRODUCTION: THE RISE OF A NEW PHENOMENON}

Competition on the global market forces many organizations and enterprises to make use of new technology and applications to reduce time and at the same time cut down the costs of their IT - infrastructure [3]. So it is important to maintain a very high degree of resilience with respect to the IT infrastructure. With the rise of a ubiquitous provision of computing resources over the past years, Cloud Computing gaining interest lately. Cloud Computing even refers as a new paradigm and emerging technology that flexibly offers IT resources and services over the Internet [4].

Everyone has a conception on what is Cloud Computing. It can be an ability to run a geophysical modeling application on the most powerful systems available and rent a server or a thousand of servers [15]. Cloud Computing can be seen an emerging trend to deploy and maintain software is being used by the industry such as Google, IBM, Microsoft and Amazon [5]. From a technological perspective, Cloud Computing is a steady growth of computing history that excogitated from large tabulating machines and mainframe architectures that centrally offered calculating resources via decentralized and distributed client-server architectures to personal computers [6]. Cloud Computing has the potential to revolutionize the mode of computing resource and application deployment, breaking up the traditional value chains and making room for new Information Technology Infrastructure Management - maintained off premises i.e. a third party owns and manages public cloud services and consumers using these services pay for it as per-use basis, they do not possess resources in the cloud. Thus the key concept is Virtualization [15].

Cloud Computing may be applied to solve the problems in many domains of Information Technology: Geographical Information System (GIS) and Scientific Research [5], Decision Support System [7], E- Governance System [8], ERP [9], Mobile Technology [10], Web Application Development [11] etc.

The paper starts by analyzing the IT pendulum of centralization and decentralization, after this contextual overview, briefly discusses the application of cloud computing as a computing paradigm to Information Technology Management.

\section{INFORMATION TECHNOLOGY PHASES}

How Cloud Computing fits in the pendulum of centralization and decentralization of information Technology? To better understand this we should briefly study the some major periods of evolution of IT in organization [12] -

1. The first period was 1970's. This was the era of mainframes and batch transaction processing e.g. financial statements, billing accounting systems with the end-users simply receiving the outputs (printouts).

2. The second period started in 1980's. During this period, mainframes and transaction processing moved to online. Point of Service (POS) terminals became ubiquitous and Electronic Data Interchange (EDI) became epidemic. IT was still centralized but submission interface was online and end-users directly interacting with the system by performing queries and getting reports e.g. Credit Cards, online reservation.

3. The third period happened in 1980's \& 1990's. This was time when internal business became decentralized with the PC (personal computer) revolution. In late 1990's, Venture capital caught the IT fever and this led to the burst of speculative bubble that lasted until about 2003.

4. The Wed 1.0 represented the fourth period of IT evolution and mass decentralization with full access of internet (e-mail, home banking, online shopping, social interaction)

5. The fifth period was the combination of Web 1.0 with outsourcing where the front end of the business moved to the web and back was outsourced with non-competitive transaction systems, web support and anything which could be commoditized.

6. The sixth and recent period is the combination of Web 2.0 with Cloud Computing; this means instead of virtual organization, we have virtualized organization using web 2.0 tools, net PCs, mobile technology and cloud computing services.

\section{VIRTUALIZATION: FOUNDATION FOR THE CLOUD COMPUTING}

Virtualization is the key to Cloud Computing; it is not a vague concept since virtualization is the technology allowing the inception of an intelligent abstraction layer (hypervisor) which decouples the physical hardware from the operating system to deliver greater IT resources utilization and flexibility [13]. According to VMware, Inc., the global leader in virtualization and cloud infrastructure, Virtualization is the technical foundation for cloud computing which provides automatic IT management in the cloud era to help the customers to deliver IT as a service [14]. By virtualizing our service infrastructure can provide a substantial benefits, it allows IT to completely change its deployment and usage models. On the deployment side, a lower cost has been achieved by minimizing unnecessary IT infrastructure investment. In server virtualization, different operating system shares the same hardware and while applications are running, it is easy to move the operating system between different hardware and storage virtualization makes storage a commodity [16]. 
Table 1: Technology Aspects for Virtualization (IDC White Paper 2011)

\begin{tabular}{|c|c|c|c|c|}
\hline \multicolumn{5}{|c|}{ Technology Aspects } \\
\hline $\begin{array}{l}\text { Virtualization } \\
\text { Maturity }\end{array}$ & Name & Server & Storage & Net-work \\
\hline Level 0 & Local & $\begin{array}{l}\text { Stand- } \\
\text { alone } \\
\text { PC }\end{array}$ & $\begin{array}{l}\text { Local } \\
\text { Disks }\end{array}$ & None \\
\hline Level 1 & Arena & $\begin{array}{l}\text { Client/ } \\
\text { Server, } \\
\text { N-tier }\end{array}$ & $\begin{array}{l}\text { File } \\
\text { server, } \\
\text { DB } \\
\text { server }\end{array}$ & $\begin{array}{l}\text { LAN, } \\
\text { Shared } \\
\text { Service }\end{array}$ \\
\hline Level 2 & $\begin{array}{l}\text { Data } \\
\text { Center }\end{array}$ & $\begin{array}{l}\text { Server } \\
\text { Virtuali- } \\
\text { zation }\end{array}$ & SAN & $\begin{array}{l}\text { WAN/ } \\
\text { PAN }\end{array}$ \\
\hline Level 3 & Cloud & $\begin{array}{l}\text { Cloud } \\
\text { Platform }\end{array}$ & $\begin{array}{l}\text { Cloud } \\
\text { Storage }\end{array}$ & Internet \\
\hline
\end{tabular}

\section{CLOUD COMPUTING}

\subsection{What is Cloud?}

The term Cloud Computing has been established around 2006 or 2007 to capture a particular use of IT resources (both hardware and software). Instead having static system architecture, Cloud Computing supports the delivery hosted services over the Internet. But for many years, Cloud Computing remained "a collection of related concepts that people recognized, but didn't really have a good descriptor for, a definition in search of a term, you could say" [17]. The turning point came in August 2006, when Google CEO Eric Schmidt used "Cloud Computing" in a first high profile search engine conference to describe the term Software as a Service (SaaS) with the PaaS/laaS connotations [17]. But Board definitions focus on the user perspective:

"In short, the cloud is the Real Internet, or what the Internet was really meant to be in the first place: an endless computer made up of networks of networks of computers. Even shorter: the Cloud is the Computer." [18]

“Cloud computing is the distributed virtualization of an organization's computing infrastructure."[19]

A comprehensive review conducted in 2009 by University of California Berkeley RAD Lab:

"Cloud Computing refers to both the applications delivered as services over the Internet and the hardware and systems software in the datacenters that provide those services. The services themselves have long been referred to as Software as a Service (SaaS). The datacenter hardware and software is what we will call a Cloud. When a Cloud is made available in a pay-as-you-go manner to the general public, we call it a Public Cloud; the service being sold is Utility Computing. We use the term Private Cloud to refer to internal datacenters of a business or other organization, not made available to the general public. Thus, Cloud Computing is the sum of SaaS and Utility Computing, but does not include Private Clouds" [20].

Now the U.S. Federal government has decided to use the cloud computing, so the Information Technology Laboratory of the National Institute of Standards and Technology (NIST) has given a standard definition:

"Cloud Computing is a model for enabling convenient, on-demand network access to a shared pool of configurable computing resources (e.g., network, servers, storage, applications and services) that can be rapidly provisioned and released with minimal management effort or service provider interaction." [30]

\subsection{Cloud Spectrum and Layering}

Cloud Computing provide services on different levels of abstraction including software applications, programming platforms, data storage or computing infrastructure. Wang et al. describe Platform as a Service (PaaS), which is offered as cloud computing [21] it is the combination of three complementary services, Hardware-as-a-Service (HaaS), Software-asa-Service (SaaS) and Data-as-a-Service (DaaS). They [22] were among the first who gave a unified view and comprehensive understanding of cloud computing with its relevant components. Cloud computing system fall into the following five layers as shown in Figure 1: applications, software environment, software infrastructure, software kernel, and hardware. 


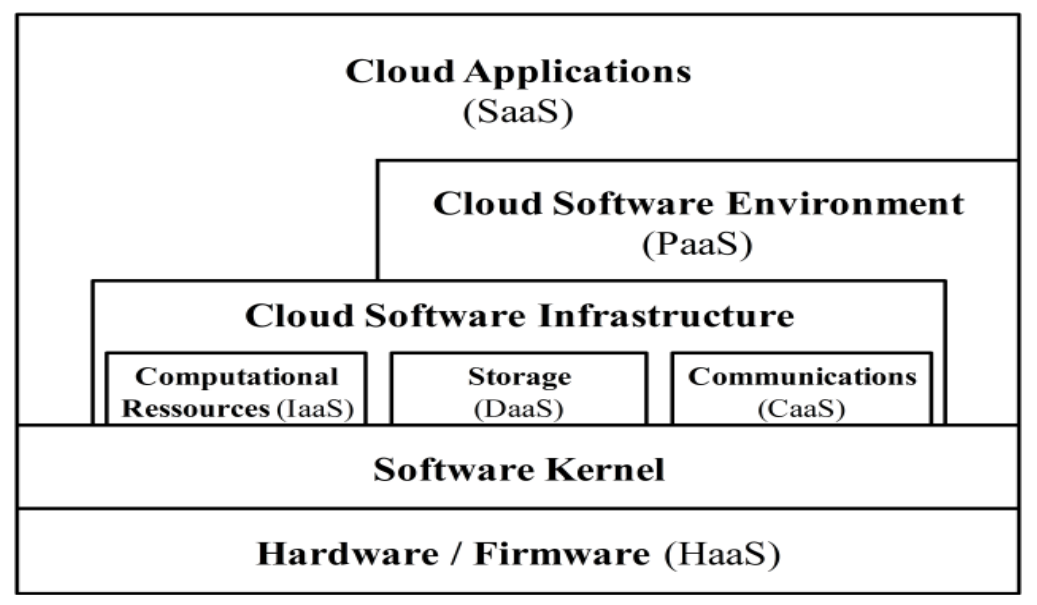

Figure 1. The Layers of Cloud Computing [22]

The cloud application layer is the most visible layer to the end of user interaction like web portals so this software provision is also referred to as Software-as-a-Service (SaaS). The cloud software environment layer provides a well defined application programming interfaces (API) to utilize cloud services and interact with other cloud applications, so this layer also referred as Platform-as-a-Service (PaaS). The cloud infrastructure layer provides resources to be utilized by cloud applications and cloud software platforms. The resources are referred to as Infrastructure-as-a-Service (laaS). Virtualization technologies are common form of providing computational resources for laaS. The Data-Storage-as-aService (DaaS) allows user to obtain demand-flexible storage which they can access from everywhere. Quality of service which is ensured by the communication capabilities such as network security, network monitoring, is provided by the new idea of Communication-as-a-Service (CaaS). The software management environment for the physical servers in datacenters is represented by the Software kernel layer. At the bottom layer Hardware-as-a-Service (HaaS) which forms the backbone of any cloud computing [22].

The use of virtualization technology, cluster technology and grid technology within the companies is for optimizing the use of their on-premise resources. So on the basis of deployment model, cloud is referred as Private Clouds (without using cloud offerings from the internet), Public Cloud (clouds that shares their resources with others). To access additional resources if the resources of the private cloud do not suffice for peak loads or if new application functions appear on the public cloud that are not available.

\section{INFORMATION INFRASTRUCTURE MANAGEMENT USING DATASENTERS \& CLOUD COMPUTING}

Before a Datacenter is built, in the area of Infrastructure as a Service, there were challenges of managing the unprecedented automation, flexibility, and efficiency to transform and deliver the IT and compute, storage, networking, security, and availability services. To address those challenges, Datacenters were created. Datacenter infrastructure management also includes planning, management and optimization. Today, we are in new technical world where anyone is allowed to sell their excess computing capacity to anyone else since the cloud computing movement underlying the datacenter infrastructure [23]. Three trends are driving the evolution:

(i) The shrinking cost of raw computing power

(ii) Virtualization for all applications

(iii) Virtualization of hardware appliances

Over the years, IT has undergone into dramatic transformation having the stages are: Pilot, the datacenter managers who are not familiar with disconnects that arise due to virtual machines sprawl and the lack of communication between IT and facilities. Consolidation, in terms of physical server cost, power, cooling and space because the IT organizations are starting to see increased virtual machine deployments and increased management costs. Assured Computing, the IT Virtual Machines (VMs) are more reliable and mobile, it is moving around the datacenter and it is critical to provide the facilities on moving VMs. So there is a possibility to have a breaker in between the racks and tripping, overheating the server. Private Cloud, to have an administrative virtual server to make processor, policies and automation tools are in place [16].

Cloud computing brings the flexibility to both the user and administrator so the federated identity helps to understand the nature of cloud authentication and how it connects with the datacenter [29]:

Connecting the User, who is accessing a local datacenter and sometimes referred as a cloud gateway.

Connecting the Application, this is hosted outside the internal datacenter \& needs to be connected.

Connecting the Data Center, this is the final piece of connection process which provides user access for both internal, data center-hosted, as well as for the external applications. 
So the Datacenter infrastructure management (DCIM) provides the increased availability stocking from the minimal use of instruments and reliability. In turn, using DCIM can save IT, money and energy.

\section{BUSINESS PERSPECTIVE IN CLOUD COMPUTING}

\subsection{Evolution of the outsourcing value chain}

A value chain is an activity that design, produce and support a product service within and around the organization not only having the different companies but also different business [24]. It also establishes the interaction between different business partners to develop and manufacture a product jointly. To do the analysis of manufacturing and production, value chain is more applicable. In IT services, value chain is divided into the areas of applications, business processes and infrastructure and referred as "plan, build, run".

In cloud computing, the value chain concept applied for outsourcing since the new trend of cloud computing leads to "as-aservice" concept not only for the software but also for the hardware based outsourcing for the data centers to computing. It shows the two big features: infrastructure based services and integrated hardware \& software as-a-service [25].

\subsection{Actors and roles in the cloud computing network}

Based on the analysis of cloud computing service providers and increased service orientation, there are following actors in the cloud market:

The customer buys services through the various channels directly through the service providers or through a platform provider [26].

Service providers develop and operate the applications that are offered and deployed on the cloud platform to access the hardware and infrastructure [27].

Aggregators can be both a customer and a service provider because they referred as specialized form of a service provider who offers new solution by combining pre-existing services or part of services to form a new service [26]

Platform provider offers a catalog in which different service providers gives the services.

Consulting is a support for the selection and implementation of the service to create a value for the business model [28].

\subsection{Information Technology and Business Benefits}

- A Single and Unified Platform for All Applications.

- A Future-Proof Data Center

- Seamless Hybrid Cloud Support

- Less Maintenance, More Innovation

- $\quad$ Greater Simplicity

- Unmatched Resource Utilization and Cost Savings

- Unprecedented Resiliency

\section{CONCLUSIONS}

Cloud computing regarded as revolutionary technology to establish an organizational concept of outsourcing. Now cloud computing extending the focus from technological perspective to a better understanding of business. It addresses the most prevailing needs flexibility, availability, reliability and also considers the economics scale. It has opened a future where 24/7 access to computing resources is given. In such world, this is not only a change in IT but a management revolution also since virtualization depends on the teams that use Web 2.0 and the cloud, to collaborate. Now "the world shifts from using Information Technology (IT) for transaction and information management to a far more organic Business Technology (BT) for collaboration and Interaction management." [18]

This is just a beginning and focus on the causes and manifestations of cloud computing having a future research on 'Cloud Computing as a disruptive innovation'.

\section{REFERENCES:}

[1] Liang-Jie Zhang, Qun Zhou, "CCOA: Cloud Computing Open Architecture," icws, pp.607-616, 2009 IEEE International Conference on Web Services, 2009.

[2] A Tata Communication White Paper, "Infrastructure- as-a-Service Fulfilling the Promise of Cloud Computing" 2010.

[3] Carr, N. G. 2005, "The end of the Corporate Computing”, MIT Sloan Management Review (46:3), pp. 32-42

[4] Fenn, I.N. Drakos, W. Andrews, R.E. Knox, et al. 2008, "Hype Cycle for Emerging Technologies, 2008 Research" (Ed, Gartner) 
[5] Daniel Oliveira and Eduardo Ogasawara Article: Is Cloud Computing the solution for Brazilian Researchers?. International Journal of Computer Applications 6(8):19-23, September 2010

[6] Freiberger, P. and M. Swaine (2000). "Fire in the Valley: the making of the personal computer." McGraw-Hill, New York

[7] W.K. Chan, Lijun Mei and Zhenyu Zhang, "Modeling and Testing of Cloud applications", to appear in Proceedings of 2009 IEEE Asia-Pacific Services Computing Conference (APSCC 2009), Singapore, December 7-11, 2009, IEEE Computer Society Press, Los Alamitos, CA, USA, 2009.

[8] K. Mukherjee and G. Sahoo., "Cloud Computing Future Framework for E-Governance", International Journal of Computer Applications 7(7):31-34. October 2010.

[9] I.Foster, Y. Zhao, I. Raicu and S. Lu, 2008, "Cloud Computing and Grid Computing 360 Degree Compared", In: Grid Computing Environments Workshop, 2008. GCE' 08 pp. 10,1

[10] Sonal Anand, Sarvesh Gupta, Shweta Fatnani, Varsha Sharma and Deepti Jain. Article: Semantic Cloud for Mobile Technology. International Journal of Computer Applications 8(12):1-4, October 2010

[11] Liladhar R Rewatkar and Ujwal A Lanjewar. Article: Implementation of Cloud Computing on Web Application. International Journal of Computer Applications 2(8):28-32, June 2010. Published By Foundation of Computer Science.

[12] Carr, N. The big switch: rewiring the world, from Edison to Google. W.W. Norton \& Co., New York, NY, 2008

[13] Chris " Poelkar, "Intelligent Storage Network," http://blogs.computerworld.com/15192/why_virtualization_is_the_foundation_of_cloud_computing December 04, 2009/4:04 PM EST [Access on 25th, Jan 2013]

[14] http://www.mainlatimes.net/index.php/technolgy/25980 virtualization foundation for cloud computing vmware, Tech Times Published on July 02, 2012 [Accessed on 25th Jan 2013]

[15] Sun Microsystems White Paper, "Introduction to Cloud Computing Architecture", June 2009

[16] IDC White Paper, "Datacenter Infrastructure Management (DCIM): Bringing Together the World of Facilities and Cloud Computing", September 2011

[17] Willis, J. “Did Google's Eric Schmidt coin 'cloud computing'?” Virtualization Journal, 2009.

[18] Finger, P. "Cloud computing set to unleash a perfect storm in business." Cordial Cloudburst, 2009.

[19] Cagle, K. "But what exactly 'is' cloud computing?" O'Reilly Broadcast, 2008

[20] Armburst, M., Fox, A., Griffith, R., Joseph, A.D., Katz, R, Konwinski, A., Lee, F., Patterson, D., Rabkin, A., Stoica, I. \&Zaharia, M. "Above the clouds: A Berkerley view of cloud computing." University of California Berkerley, Reliable Adaptive Distributed System Laboratory, Technical Report No.UCB/EECS-2009-28, (2009).

[21] Wang, W., T. Tao, M. Kunze, A. C. Castellanos, D. Kramer and W. Karl (2008). Scientific Cloud Computing: Early Definition and Experience. High Performance Computing and Communications, 2008.HPCC'08. 10th IEEE International Conference .p.825 -830

[22] Youseff L., M. Butrico and D. Da Silva (2008). Toward a Unified Ontology of Cloud Computing. Grid Computing Environments Workshop. P. 1-10

[23] Thoran Rodrigues, "Cloud Computing and the Evolution of the Data Center," Tech Republic, April 4th, 2013 [Accessed on April 25th 2013]

[24] Porter, M. E. (1985). Competitive Advantage: Creating and Sustaining Superior Performance. The Free Press, New York.

[25] Jacob, F. and W. Ulaga (2008). The transition from product to service in business markets: An agenda for academic inquiry. Industrial Marketing Management, 37 (3), 247-253.

[26] Barros, A. P. and M. Dumas (2006).The Rise of Web Services Ecosystems. IT Professional, 8(5), 31-37.

[27] Tapscott, D., D. Ticoll and A. Lowy (2000). Digital capital: haranessing the power of business Webs. Ubiquity, 1(13).

[28] Currie, W. (2000). The supply-side of IT outsourcing: the trend towards mergers, acquisitions and joint ventures. Int. journal of physical distribution and logistics management, 30 (3/4), 238-254.

[29] Bill Kleyman, "Extending the Data Center Into the Cloud," DataCenterKnowledge, Jan. 19th, 2013. [Accessed on April 25, 2013]

[30] Ciurana, Eugene, Developing with Google App Engine, New York: Springer-Verlag, 2008 


\section{Author' biography with Photo}

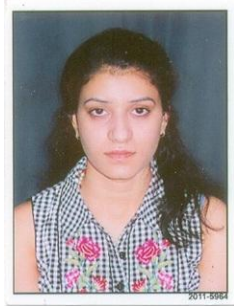

Vartika Kulshrestha is a PhD student in Banasthali University, Rajasthan, India. She received her MS degree (2009) in Wireless Sensor \& Embedded System at the University of Bradford, United Kingdom. She is working as Lecturer at Banasthali University. She is a Life Member of Indian Science Congress. Her main interest includes cloud computing, wireless sensor networks, cryptography, embedded system..

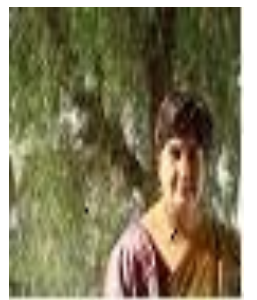

Dr. Seema Verma obtained her Master and Ph.D degree in Electronics from Banasthali University in 1999 \& 2003. She is currently working as Associate Professor of Electronics and Head, Department of Aviation Sciences at Banasthali University. She is Fellow of IETE, Life Member of Indian Science Congress, Life member of International Association of Engineers, (IAENG). She is in the Pearl edition of Who's Who in the World (2013). She is an active research supervisor and 4 Ph.Ds have been awarded under her guidance. She has been frequently invited to present invited or plenary keynote lectures at international conferences in India \& abroad. She has presented many papers in various international conferences. She has published many research papers in various journals of repute. She has many projects from UGC (under R7D Major research project Scheme, UGC Innovative Course Scheme) \& AICTE to her credit. She is currently into the editorial board of many international journals in the field Wireless Communication and Coding. Her research areas are Coding theory, TURBO Codes, Wireless sensor networks, Aircraft Ad-hoc networks, Network Security \& VLSI Design.

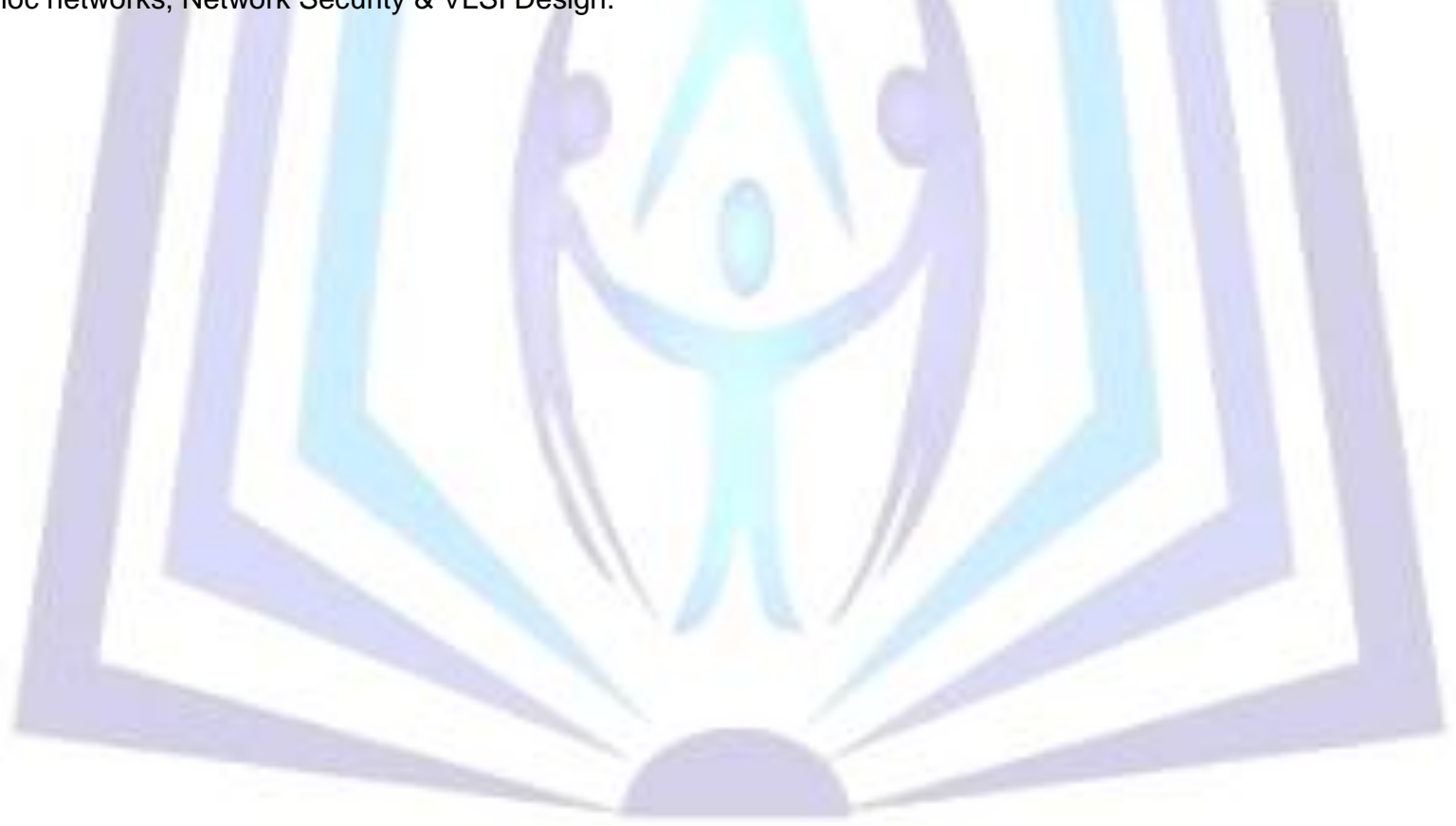

